\title{
Stimulus control of topographically tagged responding
}

\author{
K. GEOFFREY WHITE and STEVEN B. BRAUNSTEIN \\ Victoria University, Wellington, New Zealand
}

\begin{abstract}
Pigeons' responses on an operant key were reinforced according to either multiple variableinterval variable-interval or multiple variable-interval extinction schedules. The multiple-schedule components were signaled by line-tilt stimuli on a second key (signal key). Signal-key responses never produced reinforcement, and operant-key responses were not reinforced if they followed within $1 \mathrm{sec}$ of a signal-key response. Behavioral contrast was not observed on the operant key, although there was a small, but reliable, increase in signal-key responding in the variableinterval component of the multiple variable-interval extinction condition. Generalization tests were interspersed between sessions of multiple variable-interval extinction training. Generalization gradients along the line-tilt dimension exhibited peak shift for both operant-key and signalkey responding following intradimensional (line tilt) discrimination training. Line-tilt generalization gradients following interdimensional discrimination did not exhibit peak shift. Gradients following intradimensional discrimination were sharper than gradients following interdimensional discrimination for both operant-key and signal-key responding. It was concluded that dimensional stimulus control of topographically tagged responding maintained by the stimulusreinforcer relation parallels that maintained by the response-reinforcer relation.
\end{abstract}

Catania (1973) has shown how behavior may be analyzed into its components by topographical tagging. When responding on a single manipulandum is under the control of two or more such separable classes of variables as reinforcement rate, the different sources of control may be identified by restricting the scheduled response-reinforcer relations to different manipulanda. Thus, behaviors under different sources of control are tagged according to response location.

Keller (1974) has applied the topographical tagging analysis to discrimination learning in multiple schedules. In a standard two-component multiple schedule, two stimuli alternate in succession, and each is associated with an independent schedule of reinforcement. When reinforcement rates in the components differ, behavior is under the control of two contingencies: a differential response-reinforcer contingency, which results from the fact that response-contingent reinforcement occurs at different rates in the components; and a differential stimulus-reinforcer contingency, which is created by the differing associations between discriminative stimuli and reinforcement rates. There is considerable evidence that both contingencies interact in maintaining responding on a single manipulandum in multiple schedules (Schwartz

We are very grateful to Professor A. C. Catania for his valuable comments on an earlier version of the manuscript, Anthony McLean for assistance during the conduct of the experiment, and Melva Maguire and Suzette Youngblood for assistance in preparation of the manuscript. Reprints may be obtained from the first author, Department of Psychology, Victoria University of Wellington, Private Bag, Wellington, New Zealand.
\& Gamzu, 1977). For example, if the responsereinforcer relation is removed and a differential stimulus-reinforcer relation is established by associating different rates of response-independent food presentation with the different stimuli, higher response rates are observed in the component associated with the higher food density (Gamzu \& Schwartz, 1973). In pigeons, the responses are directed at-and thus "sign track" - the discriminative stimuli located on the response key (Hearst \& Jenkins, 1974; Schwartz \& Gamzu, 1977).

The aim of Keller's (1974) procedure was to separate the influences of response-reinforcer and stimulusreinforcer contingencies. In a multiple variable-interval extinction schedule (mult VI EXT), pigeons pecked at one key (the "operant key") which was always illuminated by the same constant stimulus. Operantkey responses were reinforced in the VI component but not in the EXT component. The stimuli (S1 and S2) signaling the multiple schedule components were presented on a second key (the "signal key"). Responses on the signal key had no scheduled consequences and were thereby determined by the stimulusreinforcer relation. In Keller's study, both signal-key and operant-key response rates were high in $\mathrm{Sl}$ and low in S2. By comparison, rates in nondifferential conditions (mult VI VI) were equally high in S1 and S2 for the operant key but near zero in S1 and S2 for the signal key. Keller reported positive behavioral contrast only when signal-key responding was added to operant-key responding. That is, operant-key rates in the unchanged VI (S1) component did not change from mult VI VI to mult VI EXT, whereas signal-key 
rates in S1 showed a marked increase. Similar data have been reported by Schwartz (1975).

Two further studies clarified the distinction between the topographically tagged responses. Schwartz, Hamilton, and Silberberg (1975) provided evidence that operant-key and signal-key responses were from two distinct classes-operant and respondent-as argued by Schwartz and Gamzu (1977). In their study, operant-key responses were generally of longer duration than signal-key responses. Spealman (1976), also using Keller's (1974) procedure, found that signalkey response rates decreased with increasing component duration, whereas operant-key responding and component duration were not systematically related. Both Schwartz et al. (1975) and Spealman (1976) reported higher rates at the beginnings of components (local positive contrast) for signal-key responding but not for operant-key responding. This result has been confirmed by Schwartz (1978). Thus, by topographically tagging responding maintained by response-reinforcer and stimulus-reinforcer contingencies, different effects on differential responding were isolated with respect to the different contingencies. The pattern of response differential during discrimination training therefore differs for the two classes of contingency.

Dimensional stimulus control in Keller's (1974) topographical tagging procedure has not previously been explored. Dimensional control is assessed by testing for generalization along a dimension of the training stimuli. The evidence cited above points to a difference in the nature of changes in differential responding for the topographically tagged response classes. But does response probability vary as a function of stimulus value along a given dimension in the same way for operant-key and signal-key behavior? For example, is peak shift (Hanson, 1959; Thomas, 1962) common to both contingencies, or is it restricted to the signal key in the same way that behavioral contrast is (Schwartz \& Gamzu, 1977).

\section{METHOD}

\section{Subjects}

Six locally obtained homing pigeons between 1 and 4 years old at the beginning of the experiment were maintained at $80 \%$ $( \pm 10 \mathrm{~g})$ of their free-feeding body weights. All birds were experimentally naive. Water was always available in the living cages, and the prescribed body weights were maintained by supplementary feeding.

\section{Apparatus}

The interior of a standard sound-attenuated three-key chamber $(31 \times 34 \times 33 \mathrm{~cm})$ was painted matte black. General illumination was furnished by a dim houselight located on the side wall, $8 \mathrm{~cm}$ from the front of the chamber. The three translucent response keys measured $2.5 \mathrm{~cm}$ in diameter, and were located $24 \mathrm{~cm}$ above the grid floor and $10 \mathrm{~cm}$ apart, center to center. Only the left and center keys were used. The left key served as the operant key and was lit by dim white light during all components. Each operant-key response produced .05 -sec offset of the keylight; no such effect was produced by responses on the center key which served as the signal key. Closure of microswitches mounted behind both operant and signal keys required a force of approximately $.2 \mathrm{~N}$. An in-line digital display was mounted behind the center key, which could be illuminated by three 2 -mm-wide black-on-white parallel lines at seven different orientations to vertical $\left(0^{\circ}\right)$, ranging from $0^{\circ}$ to $135^{\circ}$ in $22.5^{\circ}$ steps. Masking noise was furnished by a ventilator fan and a white noise source outside the chamber. Experimental events were controlled and recorded by standard electromechanical relay apparatus located in an adjacent room.

\section{Procedure}

In Session 1, responding on the operant key was shaped according to the method of successive approximations. In Sessions 2 to 4, each of 50 operant-key responses was followed by reinforcement (3-sec access to wheat). In Sessions 5 to 8, operant-key responses were reinforced at intervals averaging $20 \mathrm{sec}$ (VI 20-sec). In each session, 6030 -sec stimulus-on periods were separated by 5 -sec time-outs during which both operant and signal keys were dark and responses produced no programmed consequence. The signal key was always dark in Sessions 1 to 8 . At no stage in the experiment did a signal-key response produce reinforcement.

Nondifferential training was conducted in Sessions 9 to 14. Operant-key responding was reinforced according to a VI 30-sec schedule in both components (mult VI 30-sec VI 30-sec). In each session, 60 30-sec components were separated by 5 -sec time-outs during which operant- and signal-key lights, but not the houselight, were turned off. In these and all future sessions, reinforcements were not delivered in the first 2 sec of each component, and any reinforcements scheduled but not obtained at the end of a component were cancelled. The components of the multiple schedule were signaled by signal-key stimuli which alternated in direct succession. The operant key was always illuminated by white light. For two pigeons (P11 and P12), the signal-key stimuli were $67.5^{\circ}$ line tilt and a blank white key. For four pigeons (P13, P14, P15, and P16), the stimuli were $67.5^{\circ}$ line tilt and $22.5^{\circ}$ line tilt. In order to minimize the possibility of an adventitious signal-keyresponse/operant-key-response chain's developing, a 1-sec changeover delay was employed: any operant-key response which followed within $1 \mathrm{sec}$ of a signal-key response was not reinforced (Spealman, 1976).

Differential training was introduced in Session 15 (mult VI 30-sec EXT). The procedure was identical to that in nondifferential training except that extinction was programmed in the presence of the blank white signal key (for P11 and P12) or in the presence of the $22.5^{\circ}$ line tilt (for P13, P14, P15, and P16). Interdimensional (67.5 $5^{\circ}$ vs. blank white) training was included so that a possible peak shift in the generalization gradient following intradimensional training $\left(67.5^{\circ} \mathrm{vs} .22 .5^{\circ}\right)$ could be identified separately from any effects specific to the line-tilt dimension employed. Thus, peak shift (as a result of intradimensional training) can be said to have occurred if the gradient mode moved from the $67.5^{\circ}$ stimulus, compared to the gradient mode obtained following interdimensional training which should remain at $67.5^{\circ}$. Differential training continued until $75 \%$ of operant-key responses were emitted in the presence of $67.5^{\circ}$ line tilt (S1). In the session following attainment of the discrimination criterion, a generalization test was administered immediately after a 20-component warm-up under the mult VI 30-sec EXT condition. The test comprised seven $30-\sec$ presentations of each of seven test stimuli $\left(0^{\circ}\right.$ to $135^{\circ}$ in $22.5^{\circ}$ steps), separated by 5 -sec time-out periods. The stimuli were randomized in blocks of seven such that each stimulus was followed by each other at least once. Generalization tests were conducted under conditions of extinction. Further generalization tests in later sessions followed three or more sessions of differential training, until three tests had been administered for P11 and P12, four for P13 and P16, and two for P14 and P15 (see Figure 1). 


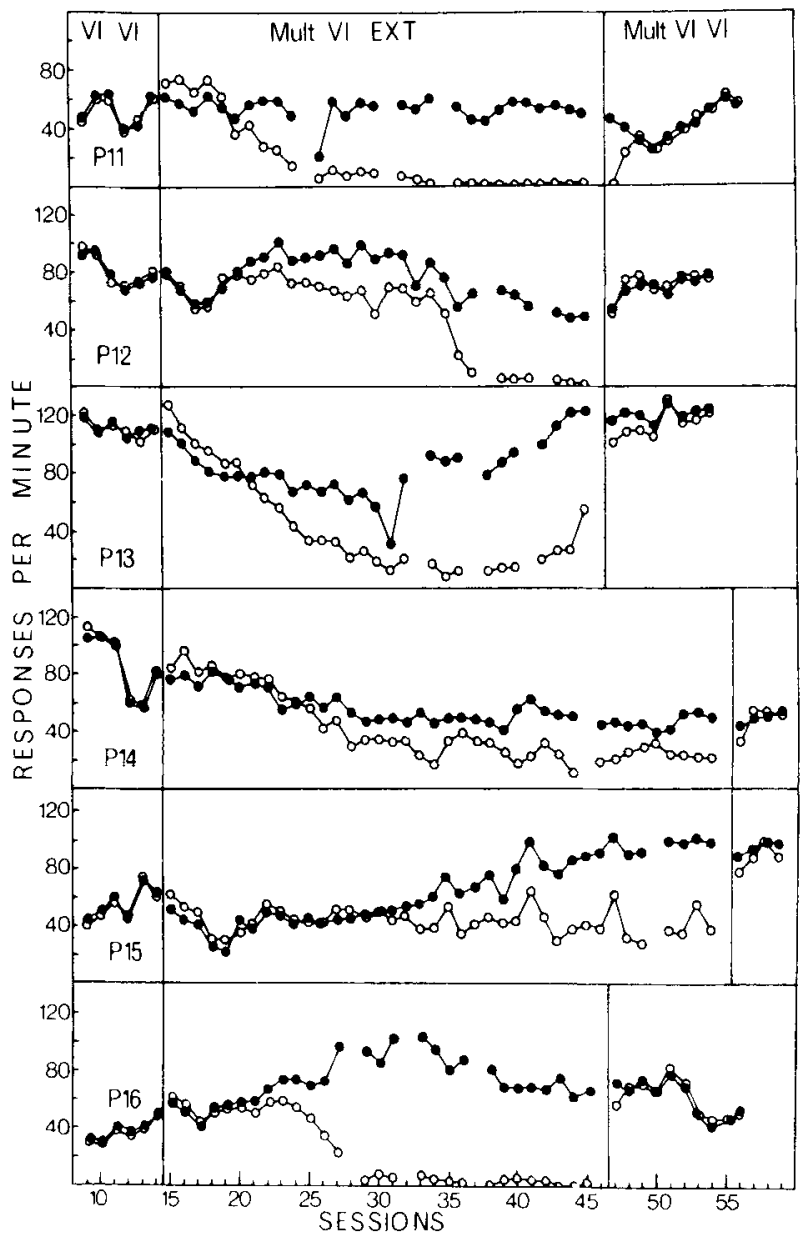

Figure 1. Rates of operant-key responding in nondifferential training (mult VI VI) and differential training (mult VI EXT), in the presence of signal-key stimuli S1 (filled circles) and S2 (unfilled circles). Unconnected points during differential training indicate sessions in which generalization tests were administered.

Beginning at Session 47 for P11, P12, P13, and P16 and at Session 56 for P14 and P15, all subjects were returned to the nondifferential mult VI 30-sec VI 30-sec condition-P14 and P15 for 4 sessions, P12 and P13 for 8 sessions, P11 and P16 for 10 sessions.

\section{RESULTS}

Session-to-session rates of responding (responses per minute) on the operant key are shown in Figure 1 for individual pigeons. All response rates were corrected for reinforcement duration. Rates in the presence of the different discriminative stimuli were similar during the nondifferential conditions and decreased in the presence of the white key (P11, P12) or $22.5^{\circ}$ line tilt (P13, P14, P15, P16) during differential training. By comparison with response rates in both nondifferential conditions, rates in S1 $\left(67.5^{\circ}\right.$ line tilt) did not exhibit the marked increase characteristic of positive behavioral contrast. That is, S1 rates were not reliably higher in the differential condition, as can be verified simply by placing a straight edge across the rates for both nondifferential conditions in Figure 1. The increases in $\mathrm{S} 1$ rates for $\mathrm{P} 13$ and P15 seem to be an order effect in that the postdiscrimination baseline rates remained high. Only in the case of P16 was there a contrast effect for operantkey responding (albeit small), but it should be noted that P16 maintained a high rate of response for six sessions after return to the nondifferential condition.

Rates of signal-key responding were generally low and were zero or near zero for one pigeon (P12). Because of the generally low level of signal-key responding, the rates were averaged over blocks of sessions. These rates (responses per minute), corrected for reinforcement duration, are presented in Table 1. For all subjects, signal-key rates were higher overall in the differential than in the nondifferential condition, and rates in the presence of $S 1$ in the differential condition were higher than S2 rates. On some few occasions, however, $\mathrm{S} 2$ rates were equal to or slightly higher than $\mathrm{S} 1$ rates in the differential condition (Table 1).

Figure 2 shows that the rates of operant-key responding (responses per minute) during each of the generalization test stimuli presented on the signal key were under the control of the line-tilt dimension. The

Table 1

Responses Per Minute on the Signal Key, Averaged over Blocks of Sessions

\begin{tabular}{|c|c|c|c|c|c|c|c|c|}
\hline \multirow[b]{2}{*}{ Subject } & \multirow[b]{2}{*}{ Stimulus* } & \multicolumn{6}{|c|}{ Sessions } & \multirow[b]{2}{*}{$56-59$} \\
\hline & & $10-14$ & $15-22$ & $23-30$ & $31-38$ & $39-46$ & $47-54$ & \\
\hline \multirow[t]{2}{*}{ P11 } & 67.5 & 0 & .6 & 1.8 & 4.3 & 2.6 & 2.4 & \\
\hline & White & 0 & .1 & .7 & .4 & .1 & .4 & \\
\hline \multirow[t]{2}{*}{ P12 } & 67.5 & 0 & 0 & 0 & .3 & 0 & .2 & \\
\hline & White & 0 & .1 & 0 & .1 & 0 & 0 & \\
\hline \multirow[t]{2}{*}{ P13 } & 67.5 & 0 & .5 & .3 & .1 & .7 & .1 & \\
\hline & 22.5 & 0 & 0 & .5 & .1 & .1 & 0 & \\
\hline \multirow[t]{2}{*}{ P14 } & 67.5 & 0 & 0 & 0 & 1.0 & 2.7 & 12.2 & 5.6 \\
\hline & 22.5 & .1 & 0 & 0 & .7 & 3.1 & 6.1 & 3.4 \\
\hline \multirow[t]{2}{*}{ P15 } & 67.5 & 0 & .1 & 1.7 & 2.7 & 4.7 & 4.2 & 2.9 \\
\hline & 22.5 & .1 & .1 & .9 & 1.9 & .6 & .6 & .8 \\
\hline \multirow[t]{2}{*}{ P16 } & 67.5 & .3 & 0 & 2.3 & 2.1 & 2.2 & 1.2 & \\
\hline & 22.5 & .3 & 0 & .3 & .1 & 0 & .6 & \\
\hline
\end{tabular}



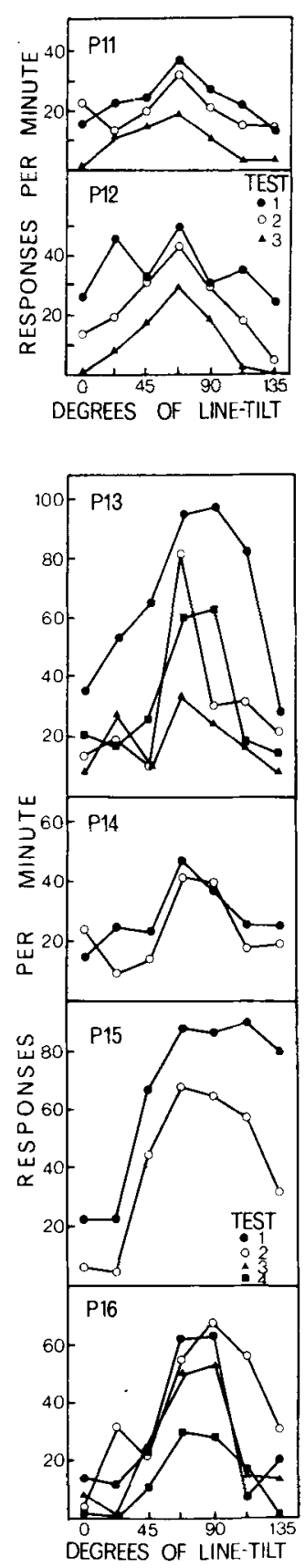

Figure 2. Line-tilt generalization gradients for operant-key responding following interdimensional training $\left(67.5^{\circ}\right.$ line tilt vs. blank white key, birds P11 and P12), and intradimensional training (67.5 $5^{\circ}$ line tilt vs. $22.5^{\circ}$ line tllt).

gradients for P11 and P12-which were trained in the interdimensional condition $\left(67.5^{\circ}\right.$ vs. blank white key)-were generally symmetrical around the S1 value $\left(67.5^{\circ}\right)$. The modal response rate was for the $67.5^{\circ}$ stimulus. The gradients for P11 and P12 were not as sharp as those for pigeons trained in the intradimensional condition $\left(67.5^{\circ}\right.$ vs. $\left.22.5^{\circ}\right)$, a result typical of the inter- vs. intradimensional comparison (Bloomfield, 1967).
Gradients for operant-key responding obtained from the first generalization test for P13, P15, and P16 exhibited peak shift. The modal value of the gradient was shifted from $67.5^{\circ}$ (S1) in the direction away from $22.5^{\circ}$ (S2). Peak shift also occurred in Test 4 for P13 and Tests 2 and 3 for P16. The only pigeon trained in the intradimensional condition which failed to exhibit peak shift was P14. Peak shift for P14 was unlikely, however, since this subject failed to maintain the discrimination throughout the differential condition. Only in the session before Test 1 was P14's discrimination ratio greater than $75 \%$. For most other sessions, the ratio was less than $70 \%$ (Figure 1), thus indicating weak intradimensional discriminative control, without which peak shift should not occur (Wheatley \& Thomas, 1974).

Rates of signal-key responding (responses per minute) during the generalization tests were very low, and were therefore averaged across tests (Figure 3). Notwithstanding the weakness of any conclusions based on such low response rates, the gradients in Figure 3 indicate that signal-key responding was under dimensional stimulus control. Furthermore, the signal-key gradients generally paralleled those for operant-key responding in that intradimensional gradients were sharper than interdimensional gradients, and the gradients for P13, P15, and P16 exhibited peak or area shift.

\section{DISCUSSION}

By topographically tagging responding in multiple schedules, the procedure of the present experiment separated the locus of the effects of response-reinforcer and stimulus-reinforcer contingencies (Catania, 1973; Keller, 1974; Schwartz \& Gamzu, 1977). With the

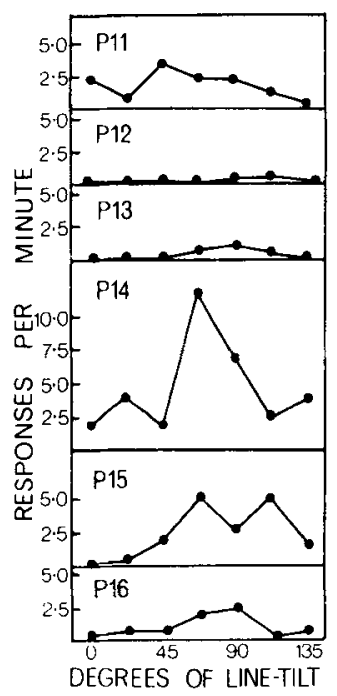

Figure 3. Line-tilt generalization gradients for signal-key responding, averaged over tests. 
possible exception of one pigeon, an increase in response rate in the constant component of the differential condition (S1) did not occur for operant-key responding, but there were reliable, although small, S1 rate increases for signal-key responding. These data are entirely in agreement with previous studies (Keller, 1974; Schwartz, 1975; Schwartz, Hamilton, \& Silberberg, 1975; Spealman, 1976), and provide further support for the "additivity theory" of behavioral contrast. According to additivity theory, the differential stimulus-reinforcer contingency in a multiple schedule elicits responses which are "added to" the rate of responding controlled by the response-reinforcer contingency. The theory assumes that the additional responses that occur in positive contrast are directed towards or "sign track" the discriminative stimuli (Hearst \& Jenkins, 1974). Thus, a rate increase is expected for signal-key and not for operant-key responding in the topographical tagging procedure (Keller, 1974; Schwartz, 1975). Evidence for additivity theory is fully summarized by Schwartz and Gamzu (1977). It should be noted, however, that signal-key responding in S1 in the present study was not frequent enough to simulate behavioral contrast. Nor was contrast simulated by adding signal-key rates to operant-key rates in Schwartz et al. (1975), or Spealman (1976). Possible reasons for the generally low rates of signal-key responding in the present study are discussed below.

The general absence of an S1 rate increase for operant-key responding but its presence for signalkey responding define a difference in differential responding maintained by response-reinforcer and stimulus-reinforcer contingencies, although both contingencies control a response differential per se in discrimination. Dimensional stimulus control for signal-key responding, assessed in terms of line-tilt generalization gradients, appeared to parallel that for operant-key responding. Peak or area shift occurred for both operant-key and signal-key responding following intradimensional discrimination, and intradimensional gradients were sharper than interdimensional gradients, again for both response topographies. One previous study provides further evidence for a parallel between dimensional control of responding tagged by response-reinforcer and stimulus-reinforcer contingencies. Tomie, Davitt, and Engberg (1976) tested for wavelength generalization following autoshaping training in which only the stimulus-reinforcer contingency was present. Gradients differed between groups given differential, nondifferential, and singlestimulus extradimensional training in exactly the same way that these conditions determined dimensional stimulus control in the equivalent free-operant procedures which included a response-reinforcer contingency (Thomas, Freeman, Svinicki, Burr, \& Lyons, 1970).

The parallel between dimensional control of operant- key and signal-key responding suggests that peak shift, unlike behavioral contrast, must be accounted for in terms of the operation of both response-reinforcer and stimulus-reinforcer contingencies. The precise determinants of peak shift in gradients obtained following training in single-key multiple schedules have been difficult to identify (Purtle, 1973; Rilling, 1977). Wheatley and Thomas (1974) have suggested that the degree of the response differential in prior training is the best predictor of peak shift. Thus, the existence of differential responding in S1 and S2 on the operant key and the signal key is sufficient for peak shift on both keys. But peak shift may be independent of behavioral contrast (Rilling, 1977), particularly in that peak shift occurred for operant-key responding in the present experiment, whereas in general behavioral contrast did not. Peak shift is a phenomenon associated with intradimensional stimulus control (Rilling, 1977), and as such can be expected in most cases where there is intradimensional control over behavior, whether that behavior is maintained by responsereinforcer or stimulus-reinforcer contingencies.

The rates of signal-key responding in the present experiment (mean of $3.65 \mathrm{rpm}$ in $\mathrm{S} 1$ for last eight sessions of differential training) were low compared to the rates reported by Keller (1974) and Schwartz (1975). Schwartz's (1975, Condition F2) pigeons averaged $14.6 \mathrm{rpm}$ in $S 1$, and the mean $S 1$ rates for Keller's (1974, Experiment 1) three pigeons were 2.2, 9.5, and $59.1 \mathrm{rpm}$. The present procedure closely resembled that of Spealman (1976), especially with respect to the COD which Schwartz, Hamilton, and Silberberg (1975) have shown decreases signal-key response rates. The S1 rates in Schwartz et al. (1975) averaged $.5 \mathrm{rpm}$. The high rates reported by Keller (1974) may have resulted from the inclusion of response-produced feedback (relay click) for signalkey pecking. In the present experiment, there were no scheduled consequences of signal-key responding. Given the generally unstable nature of stimulus-directed responding in the topographical tagging procedure (Schwartz, Hamilton, \& Silberberg, 1975) and multiple variable-time schedules (Gamzu \& Schwartz, 1973; Hamilton \& Silberberg, 1978), feedback may constitute an important source of stimulus control. Proprioceptive feedback is thought to control responding separated by short interresponse times (IRTs) in single-stimulus training, and dimensional control of short IRTs is thereby weak (Blough, 1969). But even very short IRTs are under dimensional stimulus control following intradimensional training (White, 1973). Although the present data suggest that dimensional stimulus control and peak shift are common to responding tagged by stimulus-reinforcer and responsereinforcer contingencies, microanalysis of dimensional control may reveal important differences. Prerequisite to microanalysis of the stimulus control of topo- 
graphical tagging, however, is an attempt to establish conditions under which signal-key responding is maintained at a moderately high rate.

\section{REFERENCES}

Broomfield, T. M. A peak shift on a line-tilt continuum. Journal of the Experimental Analysis of Behavior, 1967, 10, 361-366.

BLough, D. S. Generalization gradient shape and summation in steady-state tests. Journal of the Experimental Analysis of Behavior, 1969, 12, 91-104.

Catania, A. C. Self-inhibiting effects of reinforcement. Journal of the Experimental Analysis of Behavior, 1973, 19, 517-526.

GamzU, E., \& Schwartz, B. The maintenance of key pecking by stimulus-contingent and response-independent food presentation. Journal of the Experimental Analysis of Behavior, $1973,19,65-72$.

Hamiliton, B. E., \& Silberberg, A. Contrast and autoshaping in multiple schedules varying reinforcer rate and duration. Journal of the Experimental Analysis of Behavior, 1978, 30, 107-122.

Hanson, H. M. Effects of discrimination training on stimulus generalization. Journal of Experimental Psychology, 1959, 58, 321-334.

Hearst, E., \& Jenkins, H. M. Sign-tracking: The stimulusreinforcer relation and directed action. Austin, Tex: Psychonomic Society, 1974.

KELLER, K. The role of elicited responding in behavioral contrast. Journal of the Experimental Analysis of Behavior, 1974, 21, 249-257.

Purtue, R. B. Peak shift: A review. Psychological Bulletin, 1973, 80, 408-421.

RILling, M. Stimulus control and inhibitory processes. In W. K. Honig \& J. E. R. Staddon (Eds.), Handbook of operant behavior. Englewood Cliffs, N.J: Prentice-Hall, 1977.

Schwartz, B. Discriminative stimulus location as a determinant of positive and negative behavioral contrast in the pigeon.
Journal of the Experimental Analysis of Behavior, 1975, 23, 167-176.

Schwartz, B. Stimulus-reinforcer contingencies and local behavioral contrast. Journal of the Experimental Analysis of Behavior, 1978, 29, 297-308.

Schwartz, B., \& Gamzu, E. Pavlovian control of operant behavior. In W. K. Honig \& J. E. R. Staddon (Eds.), Handbook of operant behavior. Englewood Cliffs, N.J: Prentice-Hall, 1977.

Schwartz, B., Hamilton, B., \& Silverberg, A. Behavioral contrast in the pigeon: A study of the duration of key pecking maintained on multiple schedules of reinforcement. Journal of the Experimental Analysis of Behavior, 1975, 24, 199-206.

Spealman, R. D. Interactions in multiple schedules: The role of the stimulus-reinforcer contingency. Journal of the Experimental Analysis of Behavior, 1976, 26, 79-93.

Tномаs, D. R. The effects of drive and discrimination training on stimulus generalization. Journal of Experimental Psychology, 1962, 64, 24-28.

Thomas, D. R., Freeman, F., Svinicki, J. G., BurR, D. E. S., \& Lyons, J. The effects of extradimensional training on stimulus generalization. Journal of Experimental Psychology, 1970, 83(1, Part 2).

Tomie, A., DavitT, G. A., \& Engberg, L. A. Stimulus generalization of auto-shaped key-pecking following interdimensional and extradimensional training. Learning and Motivation, 1976, 7, 240-253.

Wheatley, K. L., \& Thomas, D. R. Relative and absolute density of reinforcement as factors influencing the peak shift. Journal of the Experimental Analysis of Behavior, 1974, 22. 409-418.

WhITE, K. G. Postdiscrimination generalization as a function of interresponse time. Animal Learning \& Behavior, 1973, 1, 297-301.

(Received for publication July 27, 1978; revision accepted October 6, 1978.) 